Internal fixation of the spine is carried out in only a minority of our patients, and no predominance of these among the patients who develop gastric outflow obstruction has been noted. In view of this communication we will look for any evidence of this possible, unexpected complication of spinal surgery.

Dr G. H. Ungar, MB, ChB, DPhysMed, FACRM

Deputy Medical Director Spinal Injuries Unit

Austin Hospital

Heidelberg

Victoria 3084

Australia

\title{
Reply from Professor Ohry
}

I want to thank Dr Ungar for his remarks and I wish to comment on them:

1. We still think that the AIAOD Syndrome is a very rare phenomenon. Although my clinical experience is shorter than that of Dr Ungar, may I say that during the last 15 years I have seen only 3 cases with this syndrome; 1 in Stoke Mandeville and 2 in Israel.

2. We pass a naso-gastric tube only if it is necessary and not routinely when there is evidence of ileus or sometimes in IRCU.

3. I agree that steroids have no effects in patients with complete spinal lesions.

4. In Israel and I believe in other countries as well, spinal stabilisation is sometimes required; but we have never seen AIAOD associated with lumbar internal stabilisation. Therefore we felt that it was important to report our case and we have tried to give some explanation for the phenomenon.

Professor A. Ohry, MD

Director of the Neurological Rehabilitation Department

The Chaim Sheba Medical Center

Tel Hashomer 52621

Israel 